\title{
Posture of adolescent volleyball players - a two-year study
}

\author{
Małgorzata Grabara \\ Institute of Sport Science, Jerzy Kukuczka Academy of Physical Education, Katowice, Poland
}

\begin{abstract}
Summary
Study aim: The aim of this study was to assess and compare the posture of male and female adolescent volleyball players and non-training individuals over a 2-year period.

Material and methods: The study group comprised 32 volleyball players and 30 non-athlete peers. Posture was assessed with a photogrammetric method based on the moiré phenomenon. Participants were examined 3 times at the ages of 14 , 15 and 16 years. Training experience of the studied volleyball players at the time of the $1^{\text {st }}$ measurement was less than 5 months.

Results: In volleyball players greater asymmetry in the pelvis position was noted (rotation to the right). The right scapula was more outlying than the left, and the right shoulder was more elevated than the left. Volleyball training did not result in sagittal spinal curvatures. Male non-athlete participants exhibited a significant increase in thoracic kyphosis and a decrease in lumbar lordosis over a two-year period.

Conclusion: Volleyball training affects the alignment of the pelvis, shoulder girdle and scapulae. The study revealed a number of differences in spinal curvatures between male volleyball players and non-athletes which could be associated with growth velocity and differences in body height.
\end{abstract}

\section{Key words: Asymmetries - Spine - Sagittal spinal curvatures - Moiré technique - Athletes}

\section{Introduction}

Human posture reflects one's physical and mental condition, the efficiency of the kinaesthetic sense, muscle balance and neuromuscular coordination. Posture is subject to permanent changes and is affected by numerous factors, including age, gender, body build, somatic variables, and physical activity $[13,15,26]$. The proper posture is described as symmetrical alignment of the pelvis, shoulders, and scapulae in the frontal and transverse planes. The spinous process line should overlap with the mechanical axis of the spine. Sagittal spinal curves are geometric parameters that have an impact on the mechanical properties and load balance of the intervertebral tissues [21]. Proper development of sagittal spinal curvatures is dependent on the interaction between heritable growth factors and the mechanical environment in which the spine grows [34]. Strenuous physical activity as well as exposure to intensive athletic training may affect the immature spine and can lead to a greater prevalence of morphological and functional asymmetries of the body. Intensive and regular training causes muscular hypertrophy, imbalances between agonist and antagonist muscles, decreases in flexibility as well as posture alterations $[16,19,25]$.
Many authors have indicated that sports training has an impact on both physical development and posture of children and adolescent athletes [3, 5, 8, 18-20, 28, 34]. However, changes in posture of child or adolescent athletes have seldom been studied using a longitudinal design.

Volleyball involves slight trunk flexion combined with trunk extension, rotational trunk movements in a standing position, and jumps. Serves and attacks in volleyball are performed with a number of asymmetric techniques. Asymmetric alignment of the shoulder girdle induces muscle imbalances and weakness, thus increasing the risk of shoulder injuries [31], which may result in spine asymmetry.

The objective of this study was to assess and compare the posture of male and female adolescent volleyball players with non-training individuals over a two-year period of regular volleyball training.

\section{Material and methods}

\section{Participants}

The experimental group included 13 female and 19 male volleyball players recruited from a school sports team. Their training experience at the time of the first measurement was less than 5 months. The volume of training was 
five 90-minute sessions a week in the study period. The control group consisted of 18 female and 22 male adolescents who belonged to the same school sports team. At the start of the study all participants were aged from 13 years and 6 months to 14 years and 3 months. The mean age of volleyball players was $13.9 \pm 0.33$ and of non-training participants was $13.8 \pm 0.44$. All participants were righthanded.

The following inclusion criteria for volleyball players were applied: regular participation in training over a period of two years without sustaining any injuries, attendance at all posture assessments and parental consent to participate in the study. Inclusion criteria for non-athlete individuals were as follows: non-participation in any additional sports activities, participation in physical education classes, no locomotor organ pathologies, and parental consent to participate in the study.

\section{Methods and procedures}

This study is longitudinal. The study was approved by the local Bioethics Committee and conformed to the standards set by the Declaration of Helsinki [32]. Written consent was obtained from all parents of the studied adolescents, who also completed a questionnaire to provide information on their children's training experience, sports activities, and participation in physical education classes, locomotor organ pathologies, and dominant hand. Additional information concerning the volume and frequency of training sessions, players' attendance, and their dominant hand was obtained from volleyball coaches.

Body height $(\mathrm{BH})$ was measured using an anthropometer. Body mass (BM) and fat mass (FM) [in \%] were assessed using the Tanita-410 Body Composition Analyzer (with accuracy of $0.1 \mathrm{~kg}$ and $0.5 \%$ ). The Tanita Body Composition Analyzer (Tokyo, Japan) is a device that determines body composition (e.g. percentage of fat mass) based on bioelectrical impedance analysis (BIA). The body mass index (BMI) was calculated based on BH and BM.

Posture was assessed using the photogrammetric method based on the projection of the moiré method. This method is recommended as available, inexpensive and non-invasive. It is also applied in physical therapy. The moiré method provides a 3-dimensional picture of the back and allows an analysis of over 50 posture variables with accuracy of $1 \mathrm{~mm}$ and $1^{\circ}[2,5,10,28]$. The values of correlation coefficients considering the results of roentgenograms and moiré topography in posture assessment were 0.93-0.96 [6].

Each participant adopted a habitual posture with his/ her back to the camera that recorded the image. Posture assessment lasted about 5 seconds, which did not cause postural muscle fatigue.

Analysis in the frontal, transverse and sagittal planes included:
- maximum deflection of the spinous processes from the $\mathrm{C}_{7}-\mathrm{S}_{1}$ line (DSP) [mm]; if a negative value, the spine was curved to the left side;

- alignment of the shoulder line (SL) [mm]; if a negative value, the left shoulder was more elevated than the right;

- height difference in the lower shoulder-blade angles, i.e., inclination (HSB) [mm], and depth difference of the lower shoulder-blade angles, i.e., torsion (DSB) [mm]; if the value of HSB was negative, the left scapula was more elevated than the right, and if the value of DSB was negative, the left scapula was more outlying than the right;

- pelvic lateral inclination (PL) $[\mathrm{mm}]$ and pelvic torsion (PT) $[\mathrm{mm}]$; if the value of PL was negative, the left side of the pelvis was more elevated than the right side, and if the value of PT was negative, the left side of the pelvis was more protruding;

- angular disposition of the upper segment of the thoracic curve - angle $\alpha\left[^{\circ}\right]$;

- angular disposition of the thoracolumbar segment curve - angle $\beta\left[^{\circ}\right]$;

- angular disposition of the lumbosacral segment curve - angle $\gamma\left[{ }^{0}\right]$;

- thoracic kyphosis angle (ThKA) $(\alpha+\beta)\left[^{\circ}\right]$;

- lumbar lordosis angle (LLA) $(\beta+\gamma)\left[^{\circ}\right]$;

- compensation coefficient (CC) - thoracic kyphosis angle minus lumbar lordosis angle (ThKA - LLA) $[10,12]$.

All indicators in the frontal and transverse planes were expressed as positive or negative values defining the direction of the deflection. Indicators describing alignment of the spine and pelvis were also expressed in their absolute values (av) showing the magnitude of deflection from the correct alignment without the direction of the deflection.

Three measurements were taken at the start of the study when training duration was $<5$ months, and then one and two years following the first measurement. The study participants were assessed in the morning after an overnight fast, before training or physical education classes. All participants were measured barefoot wearing only underwear.

\section{Data analysis}

The results are expressed as means and standard deviations $(\bar{x} \pm \mathrm{sd})$ of somatic variables and posture indicators. The normality of distribution and homogeneity of variance were verified with the Shapiro test and Levene's test, respectively. Results of the three measurements were compared with ANOVA for dependent samples or Friedman two-way ANOVA and Kendall's coefficients of concordance. The results of the first and the third measurements were compared with the paired samples t test or the Wilcoxon signed-rank test. The results of measurements 
of volleyball players and non-athlete individuals were compared with the $t$ test or the Mann-Whitney U test. The level of significance was set at $\mathrm{p} \leq 0.05$. The statistical analysis was performed using STATISTICA v. 13.1 software (StatSoft Inc., USA).

\section{Results}

The anthropometric data of studied adolescents are shown in Table 1.

Table 1. Somatic indicators of volleyball players and non-athlete participants (control group)

\begin{tabular}{|c|c|c|c|c|c|c|c|c|c|c|}
\hline \multirow{2}{*}{$\begin{array}{l}\begin{array}{l}\text { Study } \\
\text { parameters }\end{array} \\
\text { No. of } \\
\text { measurement }\end{array}$} & \multirow[b]{2}{*}{ Gender } & \multicolumn{3}{|c|}{$\begin{array}{l}\text { Volleyball players } \\
\qquad(\mathrm{n}=32)\end{array}$} & \multicolumn{3}{|c|}{$\begin{array}{l}\text { Control group } \\
\qquad(\mathrm{n}=40)\end{array}$} & \multicolumn{3}{|c|}{$\begin{array}{l}\text { Differences between } \\
\text { athletes and control group } \\
\text { ( } \mathrm{p} \text { value) }\end{array}$} \\
\hline & & 1 & 2 & 3 & 1 & 2 & 3 & 1 & 2 & 3 \\
\hline \multirow{2}{*}{$\mathrm{BH}[\mathrm{cm}]$} & $\mathrm{M}$ & $170.6 \pm 8.74$ & $177.1 \pm 7$ & $180.6 \pm 7.67$ & $161.4 \pm 8.06$ & $169 \pm 7.22$ & $175.2 \pm 6.62$ & 0.001 & $<0.001$ & 0.02 \\
\hline & $\mathrm{F}$ & $163.3 \pm 7.54$ & $165.6 \pm 7.2$ & $166.7 \pm 7.24$ & $159.8 \pm 7.59$ & $162.5 \pm 7.11$ & $164 \pm 6.87$ & ns & ns & ns \\
\hline \multirow{2}{*}{$\mathrm{BM}[\mathrm{kg}]$} & M & $56.5 \pm 10.47$ & $64.8 \pm 10.02$ & $69.2 \pm 8.63$ & $50.9 \pm 8.91$ & $57.6 \pm 8.3$ & $61.7 \pm 8.44$ & $\mathrm{~ns}$ & 0.021 & 0.002 \\
\hline & $\mathrm{F}$ & $54.1 \pm 10.58$ & $56.9 \pm 9.5$ & $58.1 \pm 9.79$ & $49.1 \pm 10$ & $53.2 \pm 10.37$ & $55 \pm 10.87$ & $\mathrm{~ns}$ & $\mathrm{~ns}$ & $\mathrm{~ns}$ \\
\hline \multirow{2}{*}{ BMI $\left[\mathrm{kg} / \mathrm{m}^{2}\right]$} & M & $19.25 \pm 2.08$ & $20.57 \pm 2.04$ & $21.17 \pm 1.95$ & $19.48 \pm 2.56$ & $20.13 \pm 2.23$ & $20.05 \pm 2.09$ & ns & $\mathrm{ns}$ & 0.02 \\
\hline & $\mathrm{F}$ & $20.12 \pm 2.58$ & $20.66 \pm 2.35$ & $20.83 \pm 2.61$ & $19.07 \pm 2.69$ & $20.06 \pm 3.15$ & $20.37 \pm 3.52$ & ns & $\mathrm{ns}$ & ns \\
\hline \multirow{2}{*}{ FM [\%] } & M & $8.75 \pm 2.71$ & $10.79 \pm 5.27$ & $10.35 \pm 4.15$ & $10.82 \pm 5.94$ & $9.04 \pm 4.39$ & $8.55 \pm 3.77$ & $\mathrm{~ns}$ & ns & $\mathrm{ns}$ \\
\hline & $\mathrm{F}$ & $20.56 \pm 7.84$ & $21.91 \pm 6.06$ & $24.21 \pm 6.17$ & $18.82 \pm 8.29$ & $22.8 \pm 11.63$ & $22.19 \pm 8.58$ & $\mathrm{~ns}$ & $\mathrm{~ns}$ & ns \\
\hline in. $\mathrm{BH}$ & M & & $10.1 \pm 5.46$ & & & $13.8 \pm 4.59$ & & & 0.018 & \\
\hline$\left(\mathrm{BH}_{3}-\mathrm{BH}_{1}\right)$ & $\mathrm{F}$ & & $3.4 \pm 1.69$ & & & $4.2 \pm 2.03$ & & & ns & \\
\hline
\end{tabular}

ns - not significant.

Table 2. Posture indicators in the frontal and transverse planes in male volleyball players (V) and non-athlete participants (C)

\begin{tabular}{|c|c|c|c|c|c|c|c|}
\hline \multirow{2}{*}{ Indicators } & \multirow{2}{*}{ Groups } & \multicolumn{3}{|c|}{ No. of measurement } & \multirow{2}{*}{$\begin{array}{l}\text { Intra-group } \\
\text { differences } \\
1 \text { vs. } 2 \text { vs. } 3\end{array}$} & \multirow{2}{*}{$\begin{array}{c}\text { Intra-group } \\
\text { differences } \\
1 \text { vs. } 3\end{array}$} & \multirow{2}{*}{$\begin{array}{c}\text { Inter - group } \\
\text { differences } \\
\text { V vs. C }\end{array}$} \\
\hline & & 1 & 2 & 3 & & & \\
\hline \multirow{2}{*}{ DSP av } & $\mathrm{V}$ & $5.6 \pm 2.39$ & $4.6 \pm 2.55$ & $4.1 \pm 2.23$ & ns & ns & $1: p=0.009$ \\
\hline & $\mathrm{C}$ & $4 \pm 1.45$ & $4.1 \pm 1.78$ & $3.8 \pm 2.01$ & $\mathrm{~ns}$ & ns & $2,3 \mathrm{~ns}$ \\
\hline \multirow{2}{*}{ DSP } & $\mathrm{V}$ & $-4.7 \pm 4.22$ & $-3.7 \pm 3.74$ & $-2.8 \pm 3.79$ & ns & ns & \multirow{2}{*}{ ns } \\
\hline & $\mathrm{C}$ & $-3.2 \pm 2.75$ & $-3.9 \pm 2.34$ & $-1.9 \pm 3.95$ & ns & ns & \\
\hline \multirow{2}{*}{ SL } & $\mathrm{V}$ & $-2.8 \pm 8.82$ & $-0.6 \pm 8.16$ & $-1.2 \pm 6.77$ & ns & ns & \multirow{2}{*}{ ns } \\
\hline & $\mathrm{C}$ & $-1.8 \pm 7.9$ & $-0.7 \pm 8.15$ & $2.1 \pm 10.01$ & ns & ns & \\
\hline \multirow{2}{*}{ HSB } & $\mathrm{V}$ & $3.1 \pm 11.72$ & $2.4 \pm 9.27$ & $4.2 \pm 8.75$ & ns & ns & \multirow{2}{*}{ ns } \\
\hline & $\mathrm{C}$ & $3.4 \pm 10.29$ & $2.1 \pm 11.7$ & $5 \pm 14.84$ & ns & $\mathrm{p}=0.026$ & \\
\hline \multirow{2}{*}{ DSB } & $\mathrm{V}$ & $8 \pm 10.34$ & $11.9 \pm 10.9$ & $18.8 \pm 8.04$ & $\mathrm{p}=0.005$ & $\mathrm{p}=0.005$ & \multirow{2}{*}{ ns } \\
\hline & $\mathrm{C}$ & $13.1 \pm 6.96$ & $12.3 \pm 11.18$ & $17.2 \pm 13.74$ & $\mathrm{~ns}$ & $\mathrm{~ns}$ & \\
\hline \multirow{2}{*}{ PL av } & $\mathrm{V}$ & $2.1 \pm 1.56$ & $2.4 \pm 1.82$ & $2.4 \pm 2.68$ & ns & ns & \multirow{2}{*}{ ns } \\
\hline & $\mathrm{C}$ & $1.5 \pm 1.35$ & $1.5 \pm 1.42$ & $1.5 \pm 1.42$ & ns & ns & \\
\hline \multirow{2}{*}{ PL } & V & $-0.8 \pm 2.51$ & $-1.1 \pm 2.82$ & $-1.5 \pm 3.27$ & ns & ns & \multirow{2}{*}{ ns } \\
\hline & $\mathrm{C}$ & $-0.8 \pm 1.89$ & $-1.1 \pm 1.73$ & $-0.1 \pm 2.1$ & ns & $\mathrm{ns}$ & \\
\hline \multirow{2}{*}{ PT av } & V & $6.8 \pm 5.63$ & $6.5 \pm 6.47$ & $9.6 \pm 4.09$ & $\mathrm{p}=0.016$ & $\mathrm{p}=0.013$ & \multirow{2}{*}{ ns } \\
\hline & $\mathrm{C}$ & $6.5 \pm 4.31$ & $5.7 \pm 4.53$ & $7.8 \pm 4.18$ & $p=0.047$ & $\mathrm{~ns}$ & \\
\hline \multirow{2}{*}{ PT } & V & $5.6 \pm 6.88$ & $6.1 \pm 6.83$ & $9.1 \pm 5.25$ & $\mathrm{p}=0.009$ & $\mathrm{p}=0.038$ & \multirow[b]{2}{*}{ ns } \\
\hline & $\mathrm{C}$ & $5.3 \pm 5.77$ & $4.2 \pm 6.01$ & $7.8 \pm 4.18$ & $\mathrm{p}=0.047$ & ns & \\
\hline
\end{tabular}

DSP - maximum deflection of the spinous process $\mathrm{C}_{7}-\mathrm{S}_{1}$, av - absolute values, $\mathrm{SL}$ - alignment of the shoulder line, HSB - height difference of the lower shoulder-blade angles, DSB - depth difference of the lower shoulder-blade angles, PL - pelvic lateral inclination (frontal plane), PT - pelvic torsion (transverse plane), ns - not significant. 
The analysis of the frontal and transverse plane posture indicators in male volleyball players and non-athlete participants revealed statistically significant intra-group differences in the alignment of the scapulae and the pelvis.

The analysis of these variables in female athletes and their non-athlete peers revealed statistically significant differences in the maximum deflection of the spinous process, as well as in the alignment of the shoulder girdle and the pelvis (Table 3 ).

The inter-group analysis showed significantly greater deflection of the spinous process in male and female volleyball players compared to their non-athlete peers (Table 2, Table 3).

The analysis of posture indicators in the sagittal plane showed statistically significant intra-group differences only in male non-athlete participants. These changes in the shape of spinal curvatures consisted of significant deepening of the upper thoracic curve (angle $\alpha$ ), flattening of the lumbosacral curve (angle $\gamma$ ), and the resultant predominance of thoracic kyphosis over lumbar lordosis.

The analyses of the shape of the sagittal spinal curvatures in female volleyball players and non-athletes did not reveal any significant differences (Table 4 ).

\section{Discussion}

The main objective of this study was to assess the posture of male and female adolescent volleyball players over two years of regular training in comparison to non-training individuals.

The study revealed several changes in posture indicators as effects of volleyball training. After the two-year period of training, a greater asymmetry in the pelvis and scapular positions in male volleyball players was noted. The pelvis was rotated to the right, while the right scapula was more outlying than the left. In female volleyball

Table 3. Posture indicators in the frontal and transverse planes in female volleyball players (V) and non-athlete participants (C)

\begin{tabular}{|c|c|c|c|c|c|c|c|}
\hline \multirow{2}{*}{ Indicators } & \multirow{2}{*}{ Groups } & \multicolumn{3}{|c|}{ No. of measurement } & \multirow{2}{*}{$\begin{array}{l}\text { Intra-group } \\
\text { differences } \\
1 \text { vs. } 2 \text { vs. } 3\end{array}$} & \multirow{2}{*}{$\begin{array}{c}\text { Intra-group } \\
\text { differences } \\
1 \text { vs. } 3\end{array}$} & \multirow{2}{*}{$\begin{array}{c}\text { Inter-group } \\
\text { differences } \\
\text { V vs. C }\end{array}$} \\
\hline & & 1 & 2 & 3 & & & \\
\hline \multirow{2}{*}{ DSP av } & V & $5.4 \pm 2.62$ & $4.5 \pm 2.36$ & $4.9 \pm 2.49$ & ns & ns & \multirow{2}{*}{$\begin{array}{c}3: \mathrm{p}=0.023 \\
1,2 \mathrm{~ns}\end{array}$} \\
\hline & $\mathrm{C}$ & $5 \pm 3.54$ & $4.3 \pm 2.36$ & $3.2 \pm 1.36$ & $\mathrm{~ns}$ & $\mathrm{~ns}$ & \\
\hline \multirow{2}{*}{ DSP } & V & $-3.1 \pm 5.23$ & $-2.9 \pm 4.07$ & $-2.1 \pm 5.29$ & ns & $\mathrm{ns}$ & \multirow{2}{*}{ ns } \\
\hline & $\mathrm{C}$ & $-4.5 \pm 4.19$ & $-3.3 \pm 3.76$ & $-1 \pm 3.39$ & $\mathrm{p}=0.030$ & $\mathrm{p}=0.002$ & \\
\hline \multirow{2}{*}{ SL } & V & $-3.3 \pm 7.54$ & $1.3 \pm 4.36$ & $2.4 \pm 7.75$ & $\mathrm{p}=0.050$ & $\mathrm{p}=0.046$ & \multirow{2}{*}{ ns } \\
\hline & $\mathrm{C}$ & $-0.8 \pm 4.9$ & $-0.8 \pm 8.88$ & $-1.3 \pm 6.44$ & $\mathrm{~ns}$ & $\mathrm{~ns}$ & \\
\hline \multirow{2}{*}{ HSB } & V & $0.5 \pm 9.74$ & $-0.5 \pm 7.05$ & $-2.4 \pm 6.83$ & ns & $\mathrm{ns}$ & \multirow{2}{*}{ ns } \\
\hline & $\mathrm{C}$ & $0.9 \pm 8.18$ & $-2.3 \pm 7.25$ & $-0.8 \pm 6.66$ & ns & $\mathrm{ns}$ & \\
\hline \multirow{2}{*}{ DSB } & V & $5.1 \pm 11.03$ & $10.8 \pm 9.08$ & $8.6 \pm 5.59$ & $\mathrm{~ns}$ & $\mathrm{~ns}$ & \multirow{2}{*}{ ns } \\
\hline & $\mathrm{C}$ & $9.9 \pm 8.07$ & $6.5 \pm 7.14$ & $9.7 \pm 5.93$ & $\mathrm{~ns}$ & $\mathrm{~ns}$ & \\
\hline \multirow{2}{*}{ PL av } & V & $2.3 \pm 1.31$ & $1.7 \pm 1.39$ & $2.3 \pm 2.08$ & ns & $\mathrm{ns}$ & \multirow{2}{*}{ ns } \\
\hline & $\mathrm{C}$ & $2 \pm 1.66$ & $2.1 \pm 1.45$ & $1.5 \pm 1.44$ & $\mathrm{~ns}$ & $\mathrm{~ns}$ & \\
\hline \multirow{2}{*}{ PL } & V & $-1.6 \pm 2.08$ & $-0.8 \pm 2.11$ & $-1.4 \pm 2.84$ & $\mathrm{~ns}$ & $\mathrm{~ns}$ & \multirow{2}{*}{ ns } \\
\hline & $\mathrm{C}$ & $-1.6 \pm 2.11$ & $-1.4 \pm 2.14$ & $-0.6 \pm 2.03$ & $\mathrm{~ns}$ & ns & \\
\hline \multirow{2}{*}{$\mathrm{PT}$ av } & V & $6.8 \pm 4.9$ & $9.2 \pm 7.2$ & $8.8 \pm 4.07$ & $\mathrm{~ns}$ & ns & \multirow{2}{*}{$\mathrm{ns}$} \\
\hline & $\mathrm{C}$ & $7.9 \pm 5.45$ & $7.5 \pm 5.12$ & $9.2 \pm 6.38$ & $\mathrm{~ns}$ & $\mathrm{~ns}$ & \\
\hline \multirow{2}{*}{ PT } & V & $4.4 \pm 7.3$ & $9 \pm 7.38$ & $8.8 \pm 4.07$ & ns & $\mathrm{p}=0.046$ & \multirow{2}{*}{$\mathrm{ns}$} \\
\hline & $\mathrm{C}$ & $6.5 \pm 7.2$ & $6.8 \pm 6.04$ & $8.8 \pm 6.93$ & ns & $\mathrm{ns}$ & \\
\hline
\end{tabular}

DSP - maximum deflection of the spinous process $\mathrm{C}_{7}-\mathrm{S}_{1}$, av - absolute values, $\mathrm{SL}$ - alignment of the shoulder line, HSB - height difference of the lower shoulder-blade angles, DSB - depth difference of the lower shoulder-blade angles, PL - pelvic lateral inclination (frontal plane), PT - pelvic torsion (transverse plane), ns - not significant. 


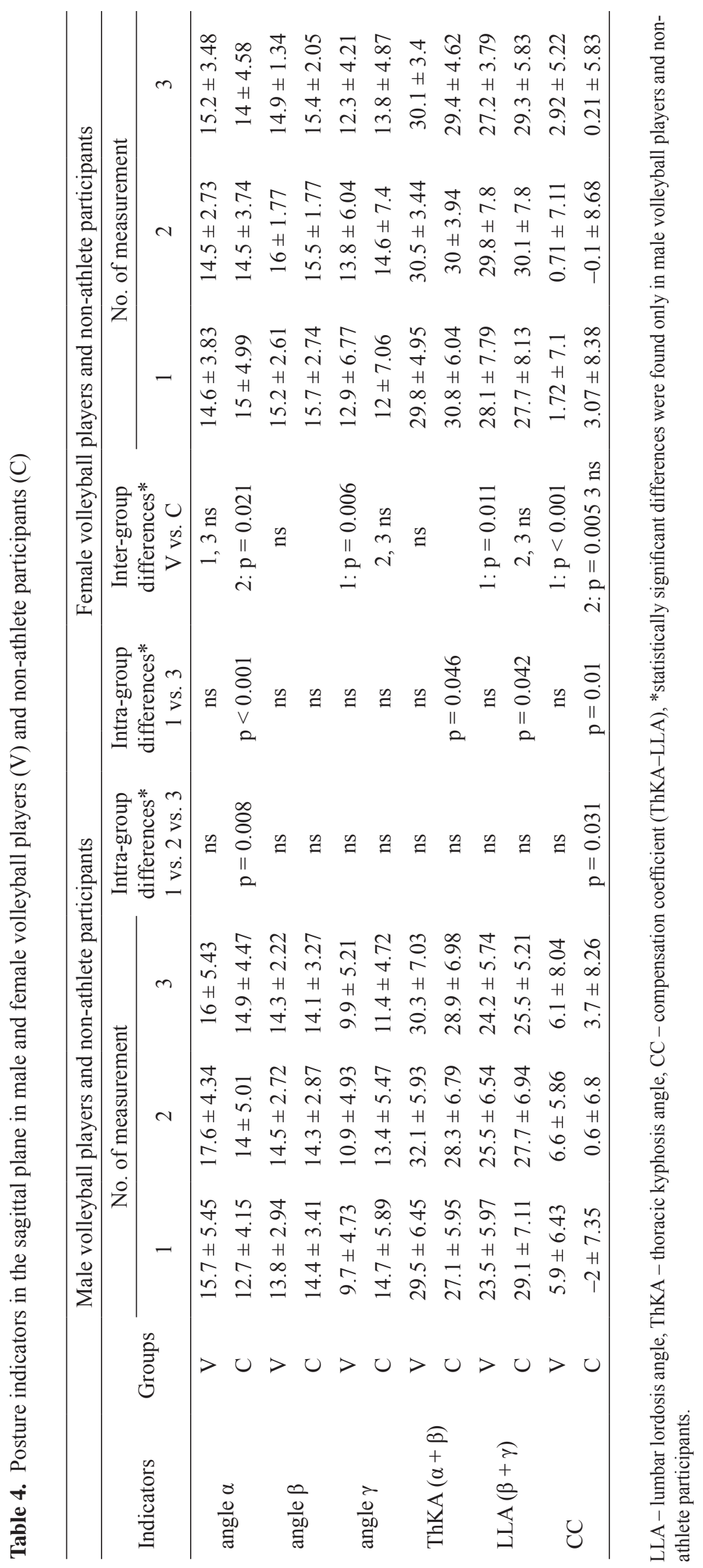


players also greater asymmetry in the pelvis was observed as well as its rotation to the right. These outcomes could be explained by frequent torso rotation performed by volleyball players while playing volleyball. The two-year period of volleyball training had an effect on the position of the shoulder girdle in female volleyball players. At the $1^{\text {st }}$ measurement the left shoulder was more elevated than the right, while at the $3^{\text {rd }}$ measurement it was the right shoulder that was more elevated. The change in alignment of the shoulder line may also be associated with performance of volleyball-specific asymmetrical movements, i.e. serves or attacks.

These results are in line with the findings of other researchers, who assumed that sports training might affect the position of the shoulder girdle, scapulae, pelvic alignment and spinal curvatures due to the specific movement patterns [3, 4, 9, 14, 23, 29]. Oyama et al. (2008) observed in overhead athletes that the dominant side scapula was more internally rotated and anteriorly tilted than the non-dominant side scapula. Those findings confirmed the scapular posture asymmetry between the dominant and non-dominant sides [24]. Ribeiro \& Pascoal (2013) reported significant differences in the scapular upwarddownward rotation and anterior-posterior tilt between dominant and non-dominant sides in volleyball players [27]. Mrozkowiak et al. (2012) observed greater asymmetry of the pelvis, shoulders and scapulae, as well as rotation of the pelvis to the left in female wrestlers aged 15 to 20 years compared to their non-athlete peers [22]. Barczyk et al. (2012) indicated greater asymmetry of scapulae in table tennis players compared to non-athletes. Those authors also noted that training experience was related to the considerable asymmetry of the shoulder girdle [2]. On the other hand, based on a study that included 245 athletes between 8 and 12 years, the authors stated that a high level of athletic training could lead to a decrease in the lateral deviation of the spine [3]. Walaszek et al. (2018) observed a corrective effect of regular 6-month judo training, e.g. progression of symmetrisation of the spine alignment and scapulae in boys aged 8 years [30]. To sum up, asymmetries observed in volleyball players could be considered typical changes related to adaptation to sports training and, what is more, should not be considered a pathological sign.

The analysis of spinal curvatures in the sagittal plane revealed a significant increase in thoracic kyphosis and a decrease in lumbar lordosis in non-athlete male participants over a two-year period. These changes may represent an effect of growth velocity. The mean increase of body height in non-athlete male participants was approximately $14 \mathrm{~cm}$ and was statistically significant compared to male volleyball players. The mean increase of body height in male volleyball players was approximately $10 \mathrm{~cm}$. The findings are in line with previous studies. Poussa et al.
(2005) and Kluszczyński et al. (2013) observed in male participants an increasing tendency for thoracic kyphosis and a decreasing tendency for lumbar lordosis that continued during growth from adolescence to early adulthood $[15,26]$. Willner and Johnson (1983) revealed a positive correlation between growth velocity and the range of thoracic kyphosis [33].

The analysis of spinal curvatures over a two-year period of volleyball training did not show any alterations resulting from volleyball training. It could be justified by the duration of regular volleyball training, which was approximately two years at the time of the $3^{\text {rd }}$ measurement. However, based on another two-year study of sagittal spinal curvatures in male adolescent basketball players and nonathlete individuals, the author indicated that basketball players exhibited age - and training time-related flattening of thoracic kyphosis, while non-athletes exhibited deepening of thoracic kyphosis [11]. On the other hand, in comparison to non-athletes, male volleyball players showed statistically significant deepening of the upper thoracic curve in the $2^{\text {nd }}$ measurement and a predominance of thoracic kyphosis over lumbar lordosis along with flattening of lumbar lordosis in the $1^{\text {st }}$ and $2^{\text {nd }}$ measurements. In the $3^{\text {rd }}$ measurement no significant differences between male volleyball players and non-athletes were observed. These findings could be explained by differences in body height.

A number of studies have confirmed the effects of sports training on spinal posture in children, adolescent and adult athletes that were not observed in the current study. Lichota et al. (2011) and Grabara (2014, 2015) observed greater thoracic kyphosis and flattened lumbar lordosis in male adolescent volleyball players $[9,10,17]$. Hyperkyphosis was seen in adolescent canoeists [18], adolescent skiers [1], rock climbers [7], and adult male cyclists [23]. Betsch et al. (2015) in their study including children between 8 and 12 years who participated in e.g. gymnastics, cycling, soccer, tennis, handball, basketball and volleyball, and who had a different number of training hours, found that increasing training time could be associated with a significant reduction of thoracic kyphosis, and a trend toward decreased lumbar lordosis angles [3].

The major limitation of the study consists of differences in somatic variables in male volleyball players compared to non-athlete participants. The other limitation is the small study population. The advantages of the study include its longitudinal design and that it was carried out among novice athletes for over two years of regular sports training.

\section{Conclusion}

The results of the present study lead to the conclusion that volleyball training affects the alignment of the pelvis, 
shoulder girdle and scapulae. In volleyball players greater asymmetry in the pelvis position (rotation to the right) was noted. The right scapula was more outlying than the left, and the right shoulder was more elevated than the left. Therefore, exercises that help maintain good posture should be included in training sessions.

\section{Conflict of interest: Authors state no conflict of interest.}

\section{References}

1. Alricsson M., Werner S. (2006) Young elite cross-country skiers and low back pain-A 5-year study. Phys. Ther. Sport, 7: 181-184. DOI: 10.1016/j.ptsp.2006.06.003.

2. Barczyk-Pawelec K., Bankosz Z., Derlich M. (2012) Body postures and asymmetries in frontal and transverse planes in the trunk area in table tennis players. Biol. Sport, 29: 129-134. DOI: 10.5604/20831862.988969.

3. Betsch M., Furian T., Quack V., Rath B., Wild M., Rapp W. (2015) Effects of athletic training on the spinal curvature in child athletes. Res. Sport Med., 23: 190-202. DOI: $10.1080 / 15438627.2015 .1005297$.

4. Cools A.M., Palmans T., Johansson F.R. (2014) Age-related, sport-specific adaptions of the shoulder girdle in elite adolescent tennis players. J. Athl. Train., 49: 647-653. DOI: 10.4085/1062-6050-49.3.02.

5. Drzał-Grabiec J. Puszczałowska-Lizis E. (2014) Analysis of selected parameters of body posture in novice divers. Polish J. Sport Med., 30: 103-111. DOI: 10.5604/1232406X.1111955.

6. El-Sayyad M.M. (1986) Comparison of roentgenography and moire topography for quantifying spinal curvature. Phys. Ther., 66: 1078-1082. DOI: 10.1093/ ptj/66.7.1078.

7. Förster R., Penka G., Bösl T., Schöffl V.R. (2009) Climber's back - Form and mobility of the thoracolumbar spine leading to postural adaptations in male high ability rock climbers. Int. J. Sports Med., 30: 53-59. DOI: 10.1055/s2008-1038762.

8. Grabara M. (2014) A comparison of the posture between young female handball players and non-training peers. $J$. Back Musculoskelet Rehabil., 27: 85-92. DOI: 10.3233/ BMR-130423.

9. Grabara M. (2014) Anteroposterior curvatures of the spine in adolescent athletes. J. Back Musculoskelet Rehabil., 27: 513-519. DOI: 10.3233/BMR-140475.

10. Grabara M. (2015) Comparison of posture among adolescent male volleyball players and non-athletes. Biol. Sport, 32: 79-85. DOI: 10.5604/20831862.1127286.

11. Grabara M. (2016) Sagittal spinal curvatures in adolescent male basketball players and non-training individuals - a two-year study. Sci. Sport, 31: e147-e153. DOI: 10.1016/j.scispo.2016.01.010.
12. Grabara M. (2018) The posture of adolescent male handball players: A two-year study. J. Back Musculoskelet Rehabil., 31: 183-189. DOI: 10.3233/BMR-170792.

13. Grabara M., Bieniec A., Nawrocka A. (2017) Spinal curvatures of children and adolescents - A cross-sectional study. Biomed. Hum. Kinet., 9: 69-74. DOI: 10.1515/ bhk-2017-0011.

14. Kibler W.B., Chandler T.J., Livingston B.P., Roetert E.P. (1996) Shoulder range of motion in elite tennis players: Effect of age and years of tournament play. Am. J. Sports Med., 24: 279-285. DOI: 10.1177/036354659602400306.

15. Kluszczyński M., Czernicki J., Kubacki J. (2014) The Plurimetric Assessment Of Spinal Curvature Changes In The Sagittal Plane In Children And Youths, Measured During 10 Years' Observation. Adv. Rehabil., 27: 5-12. DOI: 10.2478/rehab-2014-0008.

16. Krzykała M., Leszczyński P., Grześkowiak M., Podgórski T., Woźniewicz-Dobrzyńska M., Konarska A., Strzelczyk R., Lewandowski J., Konarski J.M. (2018) Does field hockey increase morphofunctional asymmetry? A pilot study. HOMO 69: 43-49. DOI: 10.1016/j. jchb.2018.03.003.

17. Lichota M., Plandowska M., Mil P. (2011) The Shape of Anterior-Posterior Curvatures of the Spine in Athletes Practising Selected Sports. Polish J. Sport Tour., 18: 112-116. DOI: 10.2478/v10197-011-0009-3.

18. López-Miñarro P.A., Muyor J.M., Alacid F. (2011) Sagittal spinal and pelvic postures of highly-trained young canoeists. J. Hum. Kinet., 29: 41-48. DOI: 10.2478/ v10078-011-0038-5.

19. López-Miñarro P.A., Vaquero-Cristóbal R., Alacid F., Isorna M., Muyor J.M. (2017) Comparison of sagittal spinal curvatures and pelvic tilt in highly trained athletes from different sport disciplines. Kinesiology, 49: 109-116. DOI: $10.26582 / \mathrm{k} .49 .1 .2$.

20. Malina R.M. (1994) Physical growth and biological maturation of young athletes. Exerc. Sport Sci. Rev., 22: 389-433. DOI: 10.1249/00003677-199401000-00012.

21. McGill S. (2002) Low back disorders: evidence-based prevention and rehabilitation. Human Kinetics, Champaign, IL.

22. Mrozkowiak M., Sokotowski M., Kaiser A. (2012) Characteristics of habitual posture in female wrestlers from the Polish National Team. Med. Sport, 65: 235-251.

23. Muyor J.M., López-Miñarro P.A., Alacid F. (2011) A comparison of the thoracic spine in the sagittal plane between elite cyclists and non-athlete subjects. J. Back Musculoskelet Rehabil., 24: 129-135. DOI: 10.3233/ BMR-2011-0286.

24. Oyama S., Myers J.B., Wassinger C.A., Ricci R.D., Lephart S.M. (2008) Asymmetric resting scapular posture in healthy overhead athletes. J. Athl. Train., 43: 565-570. DOI: $10.4085 / 1062-6050-43.6 .565$. 
25. Pinto Ribeiro C., Hanai Akashi P., de Camargo Neves Sacco I., Pedrinelli A. (2003) Relationship between postural changes and injuries of the locomotor system in indoor soccer athletes. Rev. Bras. Med. do Esporte 9: 98-103. DOI: 10.1590/s1517-86922003000200005.

26. Poussa M.S., Heliövaara M.M., Seitsamo J.T., Könönen M.H., Hurmerinta K.A., Nissinen M.J. (2005) Development of spinal posture in a cohort of children from the age of 11 to 22 years. Eur. Spine J., 14: 738-742. DOI: 10.1007/s00586-004-0701-9.

27. Ribeiro A., Pascoal A.G. (2013) Resting scapular posture in healthy overhead throwing athletes. Man. Ther., 18: 547-550. DOI: 10.1016/j.math.2013.05.010.

28. Uetake T., Ohtsuki F., Tanaka H., Shindo M. (1998) The vertebral curvature of sportsmen. J. Sports Sci., 16: 621-628. DOI: 10.1080/026404198366425.

29. Vařeková R., Vařeka I., Janura M., Svoboda Z., Elfmark M. (2011) Evaluation of postural asymmetry and gross joint mobility in elite female volleyball athletes. J. Hum. Kinet., 29: 5-13. DOI: 10.2478/v10078-0110034-9.

30. Walaszek R., Sterkowicz S., Chwała W., SterkowiczPrzybycień K., Burdacka K., Burdacki M. (2019) Assessment of body posture with the Moire's photogrammetric method in boys practising judo versus their non-sportspractising peers. Sci. Sport, 34: e187-e194. DOI: 10.1016/j.scispo.2018.08.009.

31. Wang H.K., Cochrane T. (2001) Mobility impairment, muscle imbalance, muscle weakness, scapular asymmetry and shoulder injury in elite volleyball athletes. $J$. Sports Med. Phys. Fitness, 41: 403-410.

32. Williams J.R. (2008) The Declaration of Helsinki and public health. Bull. World Health Organ., 86: 650-652.

33. Willner S., Johnson B. (1983) Thoracic kyphosis and lumbar lordosis during the growth period in children. Acta Pcediatrica, 72: 873-878. DOI: 10.1111/j.16512227.1983.tb09833.x.

34. Wojtys E.M., Ashton-Miller J.A., Huston L.J., Moga P.J. (2000) The association between athletic training time and the sagittal curvature of the immature spine. Am. J. Sports Med., 28: 490-498. DOI: $10.1177 / 03635465000280040801$.

\section{Received 14.04.2020 \\ Accepted 22.07.2020}

(C) University of Physical Education, Warsaw, Poland 